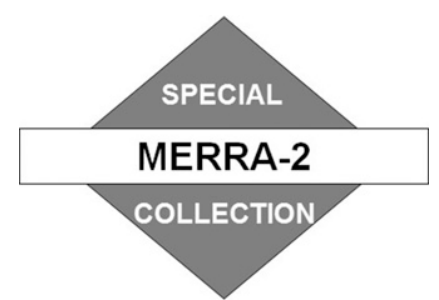

\title{
Dynamics of the Disrupted 2015/16 Quasi-Biennial Oscillation $\mathscr{O}$
}

\author{
LAWRENCE COY \\ NASA Goddard Space Flight Center, Greenbelt, and Science Systems and Applications, Inc., \\ Lanham, Maryland \\ Paul A. Newman And STEVEn Pawson \\ NASA Goddard Space Flight Center, Greenbelt, Maryland \\ LESLIE R. LAIT \\ NASA Goddard Space Flight Center, Greenbelt, and Goddard Earth Sciences Technology and \\ Research, Morgan State University, Baltimore, Maryland
}

(Manuscript received 5 September 2016, in final form 27 March 2017)

\begin{abstract}
A significant disruption of the quasi-biennial oscillation (QBO) occurred during the Northern Hemisphere (NH) winter of 2015/16. Since the QBO is the major wind variability source in the tropical lower stratosphere and influences the rate of ascent of air entering the stratosphere, understanding the cause of this singular disruption may provide new insights into the variability and sensitivity of the global climate system. Here this disruptive event is examined using global reanalysis winds and temperatures from 1980 to 2016. Results reveal record maxima in tropical horizontal momentum fluxes and wave forcing of the tropical zonal mean zonal wind over the NH 2015/16 winter. The Rossby waves responsible for these record tropical values appear to originate in the $\mathrm{NH}$ and were focused strongly into the tropics at the 40-hPa level. Two additional NH winters, 1987/88 and 2010/11, were also found to have large tropical lower-stratospheric momentum flux divergences; however, the QBO westerlies did not change to easterlies in those cases.
\end{abstract}

\section{Introduction}

The quasi-biennial oscillation $(\mathrm{QBO})$ consists of downward descending easterly and westerly zonal wind regimes that dominate the zonal mean wind variability in the tropical lower stratosphere $(100-10 \mathrm{hPa}, \sim 18$ $30 \mathrm{~km}$ in altitude) with a varying ( $\sim 28$ month) period [see Baldwin et al. (2001) and references therein]. The QBO has been a persistent characteristic of the tropical lower stratosphere since observations began in 1953. However, a significant disruption of the QBO occurred during the Northern Hemisphere (NH) winter of 2015/16

Supplemental information related to this paper is available at the Journals Online website: http://dx.doi.org/10.1175/ JCLI-D-16-0663.s1.

Corresponding author: Lawrence Coy, lawrence.coy@nasa.gov
(Newman et al. 2016; Osprey et al. 2016), and several features of this singular disruption imply that a different mechanism may have been responsible for the disrupting accelerations than the vertically propagating waves responsible for the QBO. Most noticeably, anomalous easterly accelerations occurred in the center of the QBO westerlies, a region of weak vertical wind shear, rather than in the strong vertical wind shear regions as has been typically observed.

Vertically propagating equatorial waves are believed to be the principal forcing mechanism of the QBO (Lindzen and Holton 1968). Selective filtering of vertically propagating waves by the QBO wind distribution coupled with the tendency of the waves to break or thermally dissipate, deposit momentum, and thereby dissipate in regions of the QBO wind shear produce appropriately signed zonal wind accelerations that effectively lower the shear regions by approximately 
$1 \mathrm{~km} \mathrm{month}{ }^{-1}$. Thus, the strength of the wave forcing determines the QBO period. The waves responsible are a mix of global-scale eastward-propagating Kelvin waves, westward-propagating equatorial Rossby gravity waves, and smaller-scale eastward- and westward-propagating gravity waves, all originating in the troposphere (Holt et al. 2016). Even relatively small zonal accelerations can build strong equatorial winds over time as the lack of the Coriolis force at the equator enables the winds to continue in the direction of the acceleration rather than turning as at midlatitudes.

In contrast to the typical downward propagation of the QBO, based on wave-induced accelerations in the regions of vertical wind shear, Newman et al. (2016) and Osprey et al. (2016) found easterlies developing in the region of strong westerlies. Examination of the tropical zonal momentum budget by Osprey et al. (2016) showed that the divergence of the horizontal Eliassen-Palm (EP) flux component (see Andrews et al. 1987, p. 128) was responsible for the anonymous easterly acceleration near $40 \mathrm{hPa}$ that characterized the 2015/16 disruption of the QBO and, in addition, that these EP flux vectors propagated into the tropics from the Northern Hemisphere. The upward and equatorward EP flux pattern noted by Osprey et al. (2016) is typical of Rossby wave propagation in the winter stratosphere (Hamilton 1982); however, the effect of Rossby waves on the equatorial winds has previously been considered to be small based on idealized model experiments that showed Rossby waves interacting with the edges of the QBO westerly jet but not changing the magnitude of the jet (O'Sullivan 1997). Given the structure of the anomalous QBO evolution observed during 2015/16, the potential of Rossby waves to significantly affect the QBO needs to reexamined.

Another possible QBO disruption mechanism would be barotropic instability in the equatorial region. Shuckburgh et al. (2001) showed extensive regions of potential barotropic instability associated with QBO westerlies. The relatively small vertical scale of the anomalous easterly acceleration, centered on approximately $40 \mathrm{hPa}$, suggests that barotropic instability may be working to reduce the latitudinal wind shear in the region of strong westerlies. In addition to wave forcing, we consider the possibility of these local wind shear instabilities.

To characterize the wave forcing responsible for the disruption of the QBO, we examine the Rossby wave equatorial momentum forcing during the 2015/16 NH winter using global reanalysis winds and temperatures from 1980 to 2016. This extends the analysis of Osprey et al. (2016) by placing the 2015/16 momentum forcing in the context of a 36-yr reanalysis climatology. We will also examine the possibility of barotropic instability at $40 \mathrm{hPa}$ during the 2015/16 NH winter. After describing the datasets used and the analysis procedure (section 2), we present the mean equatorial momentum fluxes and their divergences along with the evolution of the zonal mean zonal wind (section 3 ), followed by a summary and discussion of the results (section 4).

\section{Data and methods}

For this study, we use output collections from the Modern-Era Retrospective Analysis for Research and Applications, version 2 (MERRA-2; Bosilovich et al. 2015), including 3-hourly instantaneous output on model levels (GMAO 2015b) and monthly averages on constant pressure levels (GMAO 2015c). The model levels are approximately $1 \mathrm{~km}$ apart in the lower stratosphere with approximately 14 levels between 100 and $10 \mathrm{hPa}$. In the stratosphere, the pressure levels are 100, 70, 50, 40, 30, 20, $10,7,5,4,3,2$, and $1 \mathrm{hPa}$. MERRA-2 begins in January 1980 and is ongoing. The stand-alone MERRA-2 model component generates its own QBO, based on both resolved waves and parameterized gravity wave drag (Molod et al. 2015; Holt et al. 2016), thereby reducing reliance on observations for the assimilated QBO (Coy et al. 2016). Time altitude cross sections of the MERRA-2 QBO zonal mean zonal winds from 1980 to 2012 are shown in Kawatani et al. (2016). [Note that all equatorial averages here are based on a $10^{\circ} \mathrm{S}-10^{\circ} \mathrm{N}$ average except for Fig. 4, which is based on averages over $5^{\circ} \mathrm{S}-5^{\circ} \mathrm{N}$ for direct comparison with Osprey et al. (2016, their Fig. 2b).]

A QBO composite from MERRA-2 was generated based on the date of the change from zonal mean easterlies to westerlies at $30 \mathrm{hPa}$. The zonal mean zonal winds from the 3-h collection were averaged over a day and from $10^{\circ} \mathrm{S}$ to $10^{\circ} \mathrm{N}$ before selecting the composite dates of the wind sign change. The composite QBO averages different times of year so that the annual and semiannual cycles tend to average to zero; however, the specific years examined, 2014-16, have both annual and semiannual cycles present. To compare without the annual and semiannual cycles, the monthly averages over the years 1980-2014 were removed when constructing the deviation of 2014-16 from the composite (Fig. 1c). This procedure mainly removed a semiannual signal at the upper levels shown along with a smaller annual signal. The standard deviation of the composite (Fig. 1d) was multiplied by a factor of $\sqrt{2}$ to estimate the amplitude of the variability.

The EP flux vectors (see Andrews et al. 1987, p. 128) are a function of Rossby wave wind and temperature covariances. The EP flux divergence accelerates the zonal mean zonal wind. For this study, the EP flux was calculated using the monthly averaged MERRA-2 data collection. These contain the meridional heat and momentum fluxes $\left(v^{\prime} T^{\prime}\right.$ and $u^{\prime} v^{\prime}$ where $u^{\prime}, v^{\prime}$, and $T^{\prime}$ are 

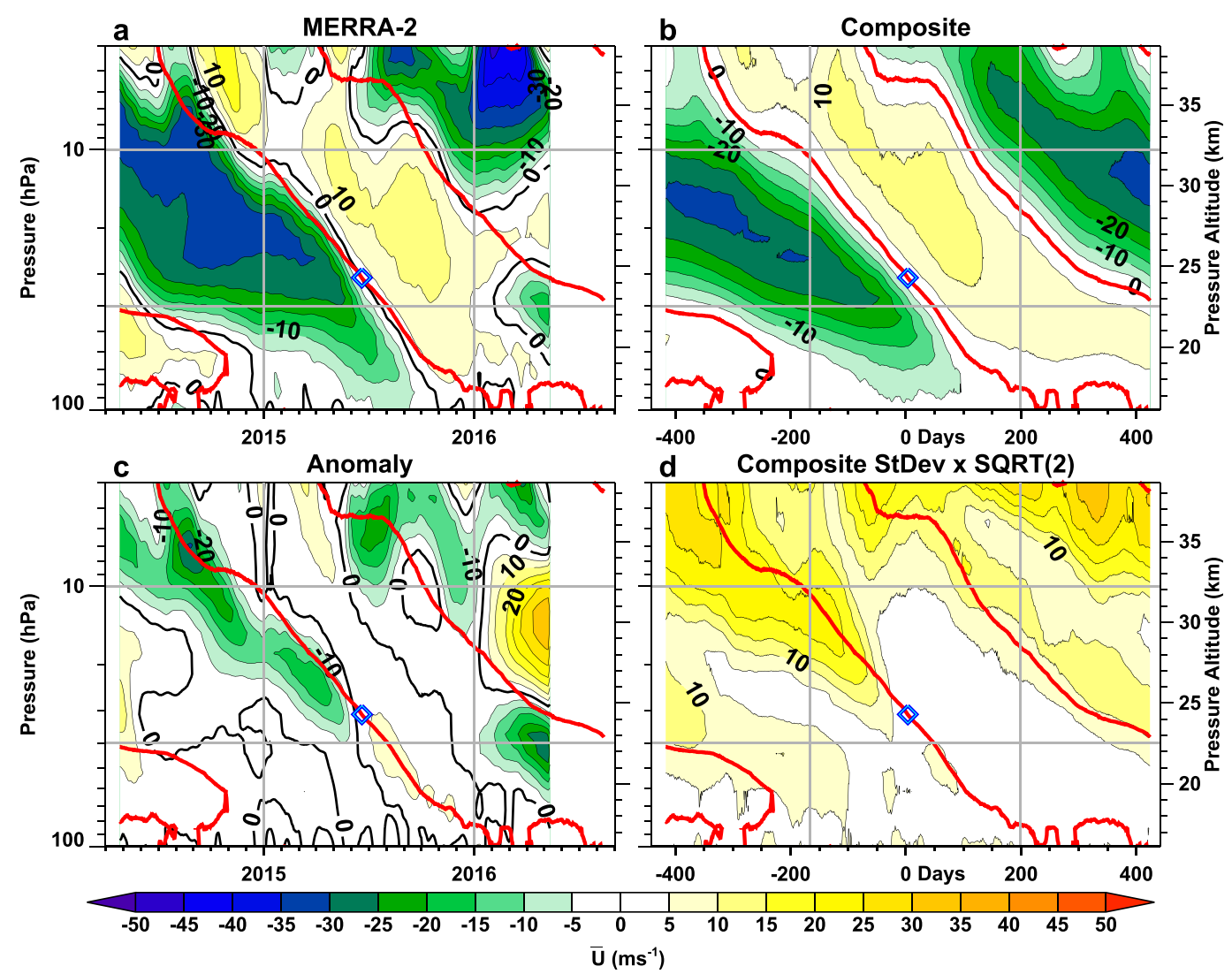

FIG. 1. Zonal mean zonal wind component $\bar{U}\left(\mathrm{~m} \mathrm{~s}^{-1}\right)$ as a function of time and pressure: (a) MERRA-2 wind analysis from May 2014 to May 2016, (b) MERRA-2 composite based on 14 easterly to westerly wind transitions at $30 \mathrm{hPa},(\mathrm{c})$ the wind analysis for 2015/16 minus the composite, and (d) the standard deviation (multiplied by $\sqrt{2}$ ) of the 14 composite members. The red contours denote the composited zero wind. The blue diamond denotes the compositing reference point. The winds are averaged from $10^{\circ} \mathrm{S}$ to $10^{\circ} \mathrm{N}$.

zonal wind component, meridional wind component, and temperature, respectively, and the prime denotes a deviation from the zonal mean) needed for the EP flux calculation. However, the vertical momentum flux $u^{\prime} w^{\prime}$ (where $w$ is vertical velocity) is not included in the monthly averaged collection, so monthly averages of $u^{\prime} w^{\prime}$ were calculated from the 3-hourly assimilation output on constant pressure levels (GMAO 2015a). Plotting the EP flux vectors can be problematic as they decrease in amplitude at upper levels and in the tropics. To address this issue, they are plotted only over a limited altitude $\left(70 \mathrm{hPa}\right.$ and above) and latitude $\left(30^{\circ} \mathrm{S}-30^{\circ} \mathrm{N}\right)$ range at the MERRA-2 constant pressure levels (see above).

We also used MERRA-2 fields from the monthly mean momentum budget files (GMAO 2015d) to distinguish between the parameterized gravity wave drag (GWD) accelerations needed to obtain a QBO in the MERRA-2 system (Molod et al. 2015) and the resolved dynamical acceleration, the sum of the dynamical and data analysis forcing. These values are accumulated at each time step and provide a breakdown of the exact momentum budget. In addition, we calculated the monthly averaged zonal mean zonal momentum forcing by the horizontal and vertical EP flux components and the residual mean circulation $\left(5^{\circ} \mathrm{S}-5^{\circ} \mathrm{N}\right)$ as in Osprey et al. (2016) based on the 3-hourly assimilation output on constant pressure levels.

Also included for February are monthly averaged EP flux vectors and EP flux divergence, normalized by their standard deviations. As the horizontal component of the EP flux vector is approximately two orders of magnitude greater than the vertical, a combination of the horizontal and vertical standard deviations (horizontal $+100 \times$ vertical) is used to normalize both components, preserving the vector directions. The factor of 100 is the order of magnitude of the ratio of the buoyancy frequency to the Coriolis parameter at midlatitudes $N / f_{o}$. Since they are normalized by the climatology, they highlight interannual variability in the flux. 
Along with the EP flux vector, we examine the heat and momentum fluxes separately. Since the tropical momentum and heat fluxes are generally an order of magnitude smaller than their winter midlatitude values and decrease with altitude, we have normalized these fluxes by their local standard deviations when comparing their relative values during individual years. The monthly averaged heat and momentum fluxes (GMAO 2015c) were first zonally averaged, and then, the mean and standard deviations were calculated at each latitude and vertical level over the MERRA-2 period (19802014 ; 36 or 37 monthly averaged values). After subtracting the multiyear monthly mean, the fluxes were then divided by the monthly standard deviation for each location, providing normalized values in terms of the local standard deviations.

The response of the mean meridional circulation to the disrupted QBO was examined by calculating the residual mean meridional circulation and plotting the vertical component $\bar{w}^{*}$ using the same datasets as in the EP flux calculation described above. To focus on the perturbation, the multiyear monthly average values (December 1981-February 2015) were subtracted from each month before averaging for the winter season (December 2015-February 2016).

To assess the possibility of barotropic instability, we calculate the meridional gradient of the potential vorticity field [Andrews et al. 1987, their Eq. (5.3.4)]:

$$
\bar{q}_{\phi}=2 \Omega \cos \phi-\left[\frac{(\bar{u} \cos \phi)_{\phi}}{a \cos \phi}\right]_{\phi}-\frac{a}{\rho_{0}}\left(\frac{\rho_{0} f^{2}}{N^{2}} \bar{u}_{z}\right)_{z},
$$

where $\Omega$ is Earth's rotation frequency, $a$ is Earth's radius, $\bar{u}$ is the zonal and time average of the MERRA-2 monthly averaged zonal wind component, $\rho_{0}$ is the basic state density, $z$ is the log pressure vertical coordinate, and $\phi$ is latitude. Note that this differs slightly from the instability parameter in Shuckburgh et al. (2001), where only the meridional gradients were examined (barotropic instability). Our results showed little contribution from the term involving the vertical derivatives (baroclinic instability), so that in this case, the barotropic component of the instability requirement $\bar{q}_{y}<0$ dominates.

\section{Results}

The 2015/16 QBO was highly disrupted from its normal behavior. Figure 1 illustrates the time height structure of the MERRA-2 zonal mean zonal wind (Fig. 1a). The longitudinally dependent MERRA-2 winds, when zonally averaged, agree well with the local radiosonde winds shown in Newman et al. (2016, their Fig. 1a) and the zonally averaged assimilation winds presented in Osprey et al. (2016, their Fig. 1a). The typical zonal wind pattern descent is interrupted by anomalous easterlies developing at $40 \mathrm{hPa}$ in early 2016 along with the striking ascent of the westerly winds that began in late 2015. In comparison, the composite of the past 14 MERRA-2 QBO cycles (Fig. 1b) shows the typical descending shear zones. As in the longer radiosonde record (Newman et al. 2016), the MERRA-2 zonally averaged means show that the duration of the QBO westerlies at $40 \mathrm{hPa}$ and easterlies at $10 \mathrm{hPa}$ were approximately half of their typical duration.

The 2015/16 QBO anomaly with respect to the composite (Fig. 1c, the difference between Figs. 1a and $1 \mathrm{~b}$, with the annual and semiannual cycles removed) shows the vertical extent and timing of the QBO disruption. The easterly anomaly at $40 \mathrm{hPa}$ develops over the November 2015-April 2016 period along with the nearly simultaneous development of the westerly anomaly at $10 \mathrm{hPa}$. Note that the rapid appearance of the anomaly at all altitudes (a change over $15 \mathrm{~km}$ in altitude within a month) is much faster than the usual QBO descent rate $\left(1 \mathrm{~km} \mathrm{month}^{-1}\right)$, another indication that the 2015/16 dynamics differ from the typical QBO dynamics. The standard deviation of the 14 QBO cycle composite (Fig. 1d) shows that most of the QBO variability usually occurs in the downward progressing shear zones, in agreement with Pawson et al. (1993). Thus, the downward westerly shear zone in 2014 and early 2015 shows expected variability, while the December 2015 and later anomaly pattern occurs in regions of weak vertical wind shear and generally low variability, indicating an unexpected perturbation of the QBO.

Figure 2 shows the total zonal mean zonal momentum budget broken down into the parameterized GWD (red curve) and the resolved dynamics (blue curve). The $\mathrm{NH}$ 2015/16 resolved easterly accelerations have the largest magnitudes seen during the MERRA-2 period, peaking at $-6 \mathrm{~m} \mathrm{~s}^{-1}$ month $^{-1}$ in February 2016. In contrast, the acceleration due to the GWD parameterization, usually active during easterly accelerations, peaks at about $-2 \mathrm{~m} \mathrm{~s}^{-1}$ month $^{-1}$ in March and April 2016, only about one quarter of its typical value. These parameterized GWD accelerations are positive or very small during the months of the anomalous easterly acceleration, November 2015-February 2016, and contribute little to the momentum budget. This is because the vertical wind shear at $40 \mathrm{hPa}$ is very small during these months, and the parameterization is designed to act strongly in wind shear regions. Only after the anomalous easterlies form, creating vertical wind shear near $40 \mathrm{hPa}$, 
a

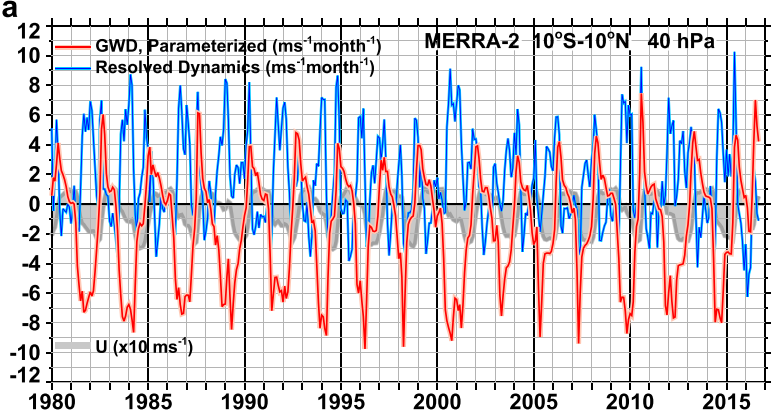

b

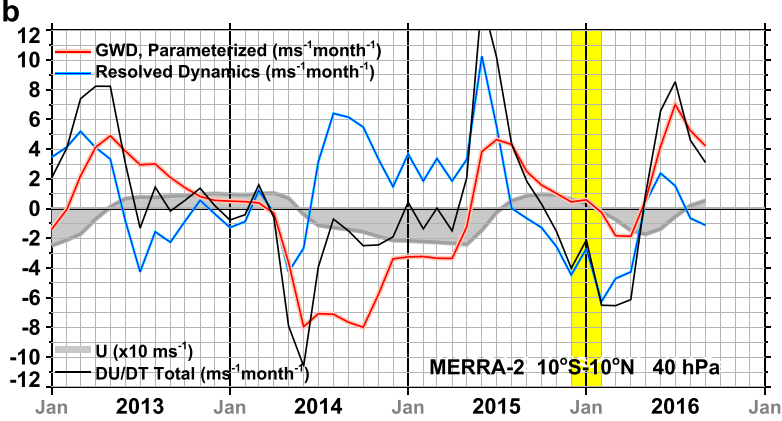

FIG. 2. (a) January $1980-$ May 2016 monthly averaged, $10^{\circ} \mathrm{S}-10^{\circ} \mathrm{N}$ averaged at 40-hPa, MERRA-2 zonal mean zonal wind acceleration due to parameterized gravity wave $\mathrm{drag}\left(\mathrm{red} ; \mathrm{m} \mathrm{s}^{-1} \mathrm{month}^{-1}\right.$ ), the resolved dynamics (blue; $\mathrm{ms}^{-1}$ month $^{-1}$ ), and zonal mean zonal wind (gray; $10^{1} \mathrm{~m} \mathrm{~s}^{-1}$ ). Vertical lines denote the start of a year. (b) Expanded time coordinate to highlight years 2013-16. Black curve in (b) denotes the sum of the red and blue curves. Yellow shading denotes months December 2015-February 2016.

did the GWD parameterization begin to contribute to the zonal momentum budget.

Some of the anomalous resolved easterly accelerations were produced by Rossby waves propagating into the equator from the NH (Osprey et al. 2016). Rossby wave activity propagation from the $\mathrm{NH}$ into the tropics is proportional to the negative of the horizontal momentum flux ( $-u^{\prime} v^{\prime}$; see Andrews et al. 1987, chapter 5). Figure 3 shows the time series of the $10^{\circ} \mathrm{S}-10^{\circ} \mathrm{N}, 40-\mathrm{hPa}$ monthly averaged horizontal momentum flux (red curve) for the MERRA-2 period. The largest peak is seen in the December 2015-February 2016 period. The February 2016 peak is about $50 \%$ greater than the January 2011 maximum. The December 2015 and January 2016 values are approximately the same as the January 2011 peak. Thus, the NH 2015/16 40-hPa level had the greatest horizontal momentum flux wave observed in the 35-yr MERRA-2 period.

As shown by Osprey et al. (2016), the divergence of the horizontal component of the EP flux during November 2015-February 2016 led to the historic easterly acceleration of the QBO westerlies at $40 \mathrm{hPa}$. Figure 3 shows the monthly averaged $10^{\circ} \mathrm{S}-10^{\circ} \mathrm{N}$ horizontal momentum flux divergences or wind acceleration a

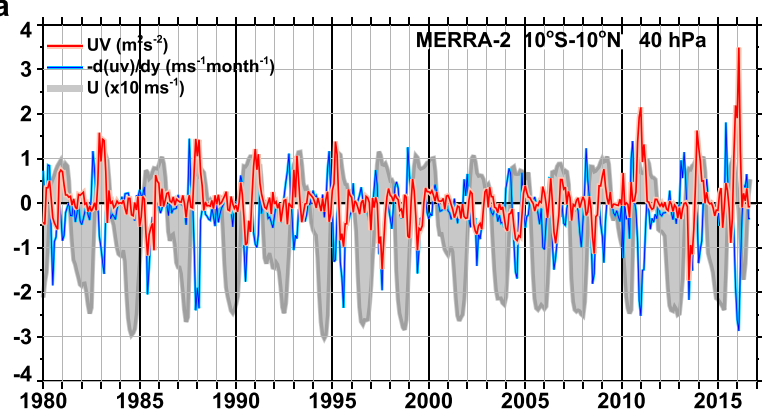

b

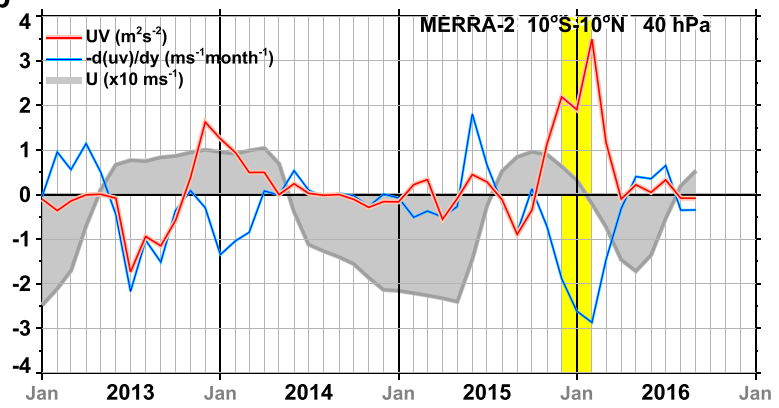

FIG. 3. As in Fig. 2, but for momentum flux (red, $\mathrm{m}^{2} \mathrm{~s}^{-2}$ ), the horizontal momentum flux divergence (blue, $\mathrm{m} \mathrm{s}^{-1} \mathrm{month}^{-1}$ ), and zonal mean zonal wind (gray, $10^{1} \mathrm{~m} \mathrm{~s}^{-1}$ ).

tendencies (blue curve) during the MERRA-2 period, where negative values contribute to a negative EP flux divergence and a negative, or easterly, zonal wind acceleration. The large amplitude negative peak corresponds to February 2016, where there were large momentum fluxes (red curve) and an easterly acceleration of the equatorial winds (gray curve). As with the momentum fluxes, the February 2016 peak is the largest seen at $40 \mathrm{hPa}$ over the 35-yr MERRA-2 period. Comparing with Fig. 2 shows that the horizontal momentum flux divergence is equal to about half of the total zonal mean zonal wind acceleration during November 2015February 2016. This implies that the remaining half of the MERRA-2 momentum budget is due to the combination of vertical momentum flux divergence and zonal mean circulations since the GWD parameterized accelerations are small during the disruption (Fig. 2).

Different analyses provide an opportunity for comparing their representation of the tropical zonal mean momentum budget during the QBO disruption. Here, we use a $\pm 5^{\circ}$ latitude average and examine the same momentum budget terms for MERRA-2 as presented in Osprey et al. (2016, their Fig. 2b) for the European Centre for Medium-Range Weather Forecasts (ECMWF) operational analysis. Four terms of the 40-hPa zonal mean momentum budget for November 2015 through April 2016 are plotted in Fig. 4. They consist of the horizontal and vertical EP flux divergence as well as 


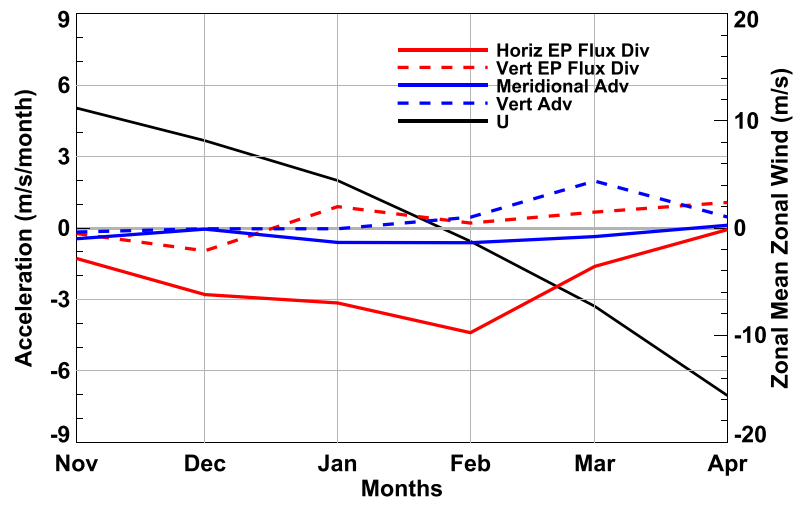

FIG. 4. Monthly averaged zonal mean zonal momentum budget terms $\left(\mathrm{m} \mathrm{s}^{-1}\right.$ month $^{-1}$, left $y$ axis) for the horizontal (solid) and vertical (dashed) EP flux divergence (red curves) and the horizontal (solid) and vertical (dashed) advection by the residual mean circulation (blue curves). Also shown is the zonal mean zonal wind (black curve; $\mathrm{m} \mathrm{s}^{-1}$, right $y$ axis). Note that the labeled acceleration units of 3,6 , and $9 \mathrm{~m} \mathrm{~s}^{-1}$ month $^{-1}$ correspond to $0.1,0.2$, and $0.3 \mathrm{~m} \mathrm{~s}^{-1}$ day $^{-1}$.

the horizontal and vertical residual mean advection. As in Osprey et al. (2016), the horizontal EP flux divergence produces the greatest easterly acceleration, peaking in February 2016, while the residual mean advection terms are relatively small. While the time behavior is similar, the magnitude of the February peak $\left(\sim 4.5 \mathrm{~m} \mathrm{~s}^{-1}\right.$ month $\left.^{-1}\right)$ is smaller than in Osprey et al. (2016; $7.5 \mathrm{~m} \mathrm{~s}^{-1}$ month $\left.^{-1}\right)$. In addition, the MERRA-2 vertical EP flux divergence remains small throughout the period shown, whereas the Osprey et al. (2016) results show larger values in MarchApril 2016. The vertical resolution differences between the two analysis system (with ECMWF having higher vertical resolution) may contribute to these differences in resolved wave momentum divergence. The missing resolved momentum in MERRA-2 is replaced by the GWD parameterization and the analysis increments so that the total momentum budget shown in Fig. 2 accurately reflects the changing zonal mean zonal wind.

The NH winter season (December-February) momentum flux divergence is examined in more detail in Fig. 5. The momentum flux divergence tends to be greater during $\mathrm{NH}$ winters with QBO westerlies (Fig. 5a). Three winters show exceptionally large magnitudes: 1987/88, 2010/11, and 2015/16, with 2015/16 being the greatest. The $1987 / 88$ and 2010/11 NH winters show a weakening followed by a strengthening of the QBO westerlies; however, mean easterlies do not develop in those winters, only during 2015/16. Like the 2015/16 NH winter, the 1987/88 winter coincided with El Niño-Southern Oscillation (ENSO); however, the 2010/11 $\mathrm{NH}$ winter was about a year after an ENSO event. Figure $5 \mathrm{~b}$ further breaks down the winter season into
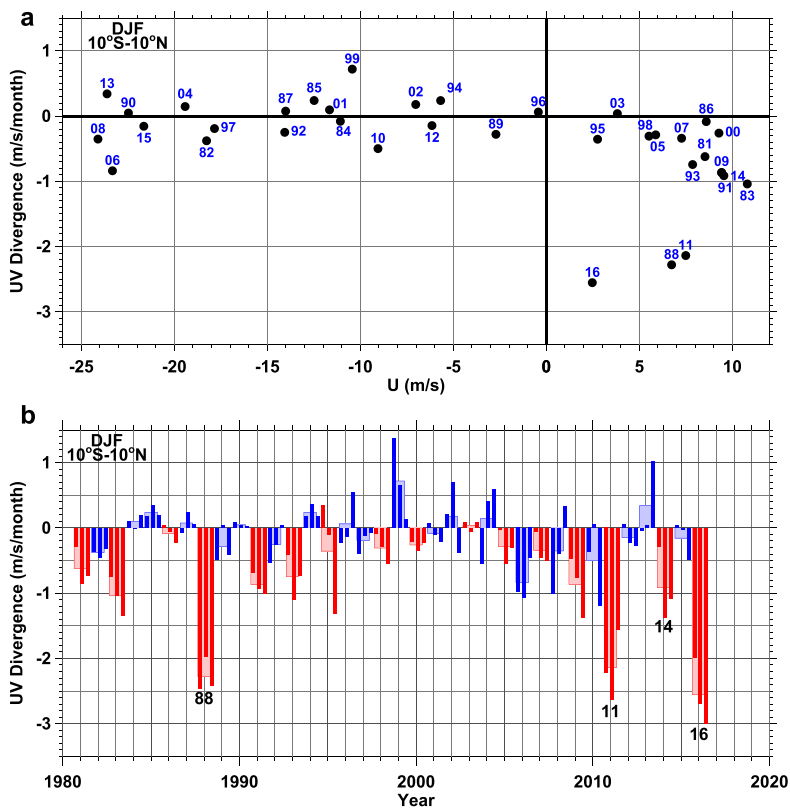

FIG. 5. Monthly mean momentum flux divergence $\left(\mathrm{m} \mathrm{s}^{-1}\right.$ month $\left.^{-1}\right)$ for NH winter (December, January, and February) plotted as (a) a function of the $10^{\circ} \mathrm{S}-10^{\circ} \mathrm{N}$ zonal mean zonal wind and (b) as a function of year. The two-digit labels denote the year for January. In (b), the winter average (wide bars) is broken down into the three monthly averages (narrow bars), where blue denotes easterly and red denotes westerly zonal mean zonal winds.

months and shows that, while corresponding months in other winters showed some with greater magnitudes, the seasonal average divergence magnitudes were greatest in 2015/16. For comparison, the most recent past westerly QBO NH winter, 2013/14, had momentum flux divergence values the were only about onethird of the 2015/16 magnitudes.

The mean flow changes can be traced backward to the subtropics using EP flux vectors. This wave propagation can be seen in the monthly mean winds and EP fluxes for the 2015/16 winter in Fig. 6. In November, the equatorial QBO westerlies are centered at about $40 \mathrm{hPa}$ with easterlies above. The November EP flux arrows show waves propagating into these westerlies and across the equator-a pattern that is not atypical for QBO westerlies. However, as shown in Fig. 6, the momentum flux divergence is much stronger than in any of the previous westerly phases. December shows wave propagation across the equator and the start of a small easterly perturbation intruding toward the equator. During the January-February period, the westerlies are split into two maxima, with development of easterlies at $40 \mathrm{hPa}$ in February (Fig. 6d) showing an EP flux pattern similar to that found in Osprey et al. (2016). In March, the easterlies are fully developed and continue to increase their 

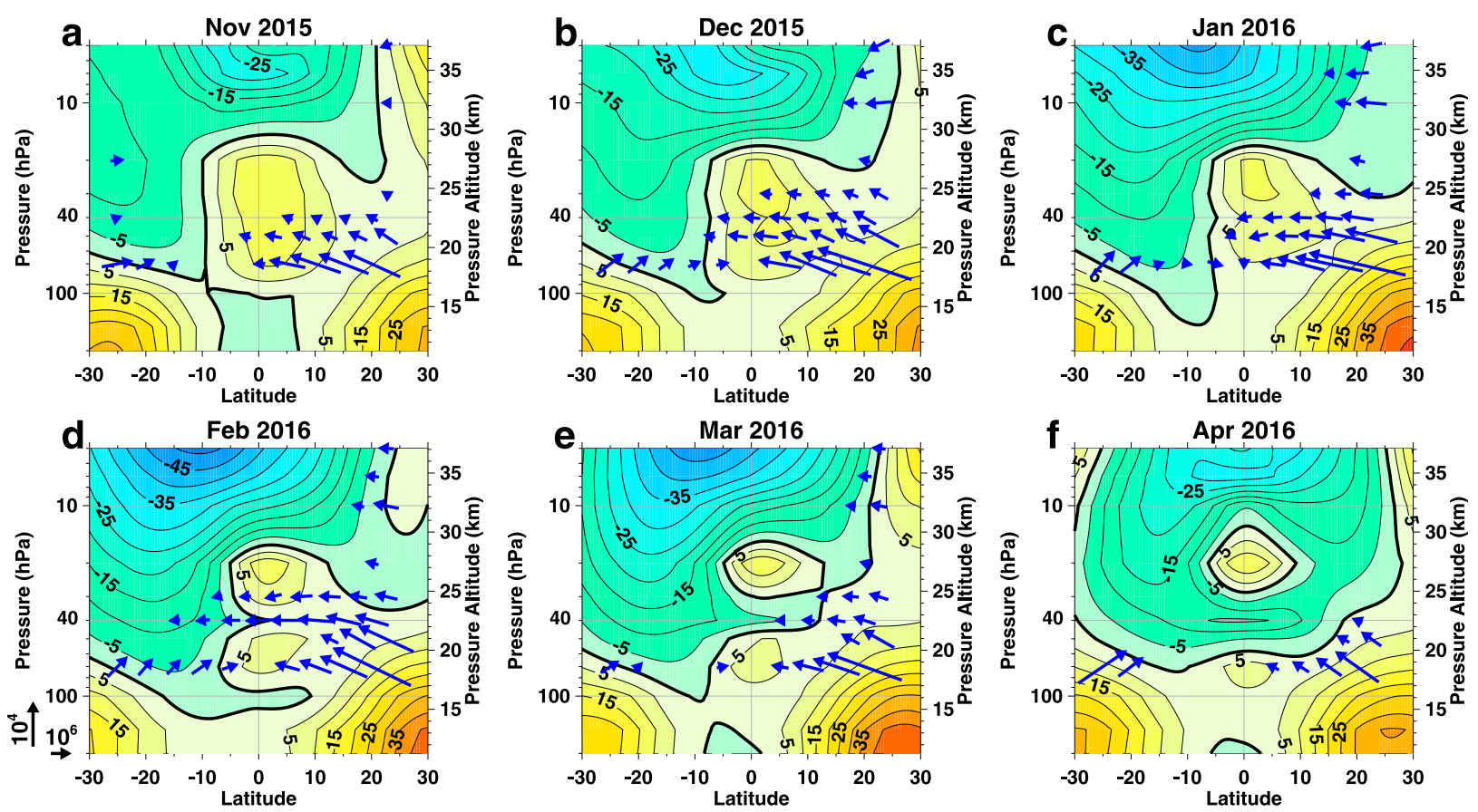

FIG. 6. Monthly averaged zonal mean zonal wind plotted from $30^{\circ} \mathrm{S}$ to $30^{\circ} \mathrm{N}$ and from 200 to $4 \mathrm{hPa}$ for the months (a) November 2015 , (b) December 2015, (c) January 2016, (d) February 2016, (e) March 2016, and (f) April 2016. Westerlies are yellow-red, and easterlies are green-blue, with $5 \mathrm{~m} \mathrm{~s}^{-1}$ contours. Also plotted are the EP flux vectors (blue arrows; scale vectors at lower left represent values of $10^{4}$ and $10^{6} \mathrm{Kg} \mathrm{s}^{-2}$ in the vertical and horizontal, respectively) at $70 \mathrm{hPa}$ and above.

vertical extent. By April, easterlies completely surround the separated upper-westerly jet. In summary, during the November-February period, the average lowerstratospheric EP fluxes extended from north to south across the equator as expected for planetary waves propagating from the $\mathrm{NH}$ to the $\mathrm{SH}$. A complete understanding of theses waves and their relatively large contribution to the momentum budget and flux (Figs. 4 and 5) needs further investigation.

Figure 7 illustrates the latitude structure of the horizontal momentum flux, the horizontal momentum flux divergence, and the meridional gradient of potential vorticity at $40 \mathrm{hPa}$ for January 1998-September 2016. This figure corresponds to the similar fields shown in Shuckburgh et al. (2001) for the 30-hPa level. The horizontal momentum flux (Fig. 7a) shows large horizontal momentum flux values extending from $30^{\circ} \mathrm{N}$ across the equatorial region during 2015/16, the time of the anomalous easterly acceleration. Other years show variability in the strength and equatorial extent of the annual cycle of momentum flux at $30^{\circ} \mathrm{N}$, with the $3 \mathrm{~m}^{2} \mathrm{~s}^{-2}$ contour also extending close to the equator during 2010/11 consistent with the large average momentum flux values seen for that winter (Fig. 2). The zonal mean zonal wind forcing created by the 2015/16 horizontal component of the momentum flux divergence (Fig. 7b) shows a corresponding strong region of easterly acceleration at the equator extending into the Southern Hemisphere at the time of the anomalous easterly acceleration. Note that the 2010/11 westerlies show a northward displacement (but not a reversal) of the latitudinal extent of the westerlies during the time of the second greatest equatorial horizontal momentum flux values in the MERRA-2 record (Fig. 2). The potential of the flow for instability $\left(\bar{q}_{\phi}\right.$; Fig. $\left.7 \mathrm{c}\right)$ shows negative regions typically at the start of the westerly phases but not during the anomalous easterly acceleration of 2015/16. Note that the larger wind meridional zonal wind shears associated with the beginning of the 2015 QBO westerlies and the time of maximum instability are apparent in Newman et al. (2016, their Fig. 2b) a plot of zonal mean zonal wind as a function of latitude and time and, furthermore, that these wind shears are greatly reduced at the start of the anomalous easterly acceleration.

Wave activity in the tropics was much higher during the 2015/16 QBO than during the recent 2013/14 QBO, where the 2013/14 winter provides a more typical example of tropical horizontal momentum flux divergence (Fig. 5). The increased wave activity in 2015 compared to 2013 is illustrated in Fig. 8, a plot of Ertel potential vorticity (EPV) at $40 \mathrm{hPa}$ averaged over December. The same mean climate EPV field has been subtracted from 

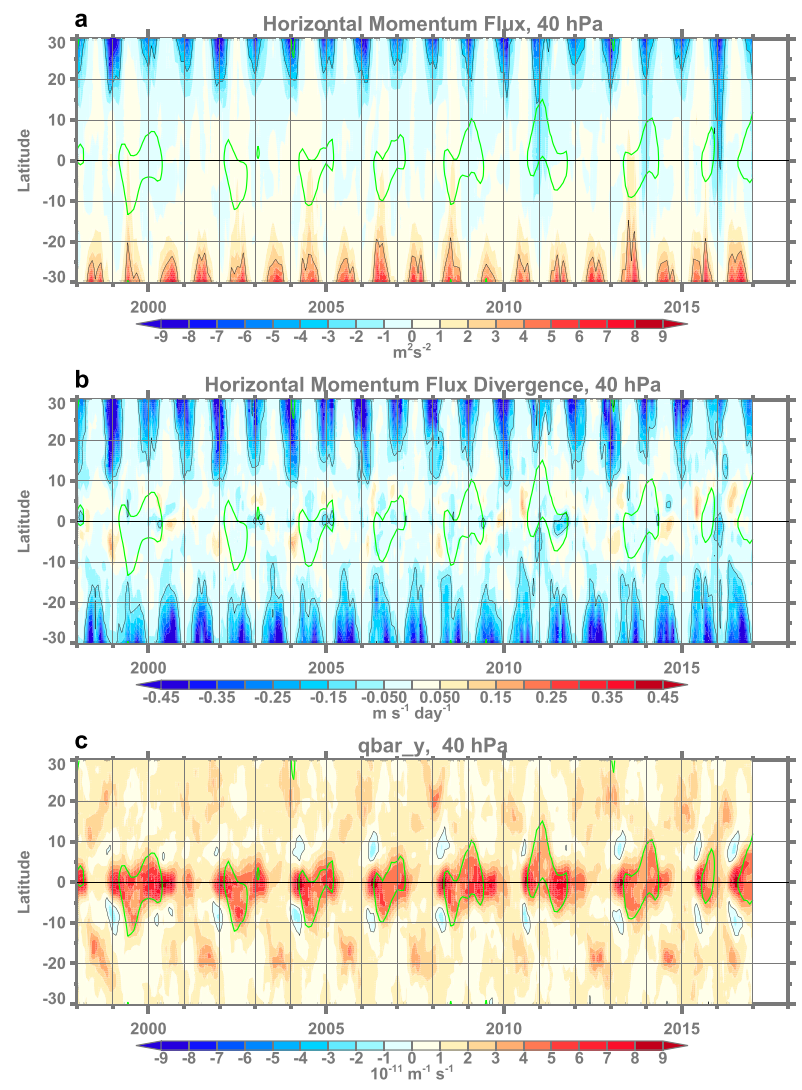

FIG. 7. Latitude-time contour plots at $40 \mathrm{hPa}$ of (a) the horizontal momentum flux $\left(\mathrm{m}^{2} \mathrm{~s}^{-2}\right)$, (b) the divergence of the horizontal momentum flux $\left(\mathrm{m} \mathrm{s}^{-1} \mathrm{day}^{-1}\right)$, and (c) the meridional gradient of potential vorticity $\left(10^{-11} \mathrm{~m}^{-1} \mathrm{~s}^{-1}\right)$. The black contours highlight the $\pm 3,-0.1$, and 0 contours in (a), (b), and (c), respectively. The green curves denote the $10 \mathrm{~m} \mathrm{~s}^{-1}$ contour of the zonal mean zonal wind.

both years to highlight the perturbations. From about $15^{\circ} \mathrm{S}$ to $30^{\circ} \mathrm{N}$, southwest to northeast sloping, EPV anomalies are seen during 2015 (Fig. 8a), while 2013 shows smaller amplitude, more zonally oriented EPV anomalies. The zero of the 40-hPa zonal mean zonal wind at this time is located at approximately $15^{\circ} \mathrm{S}$, so the 2015 EPV orientations are consistent with positive momentum fluxes in the region of westerlies. Note that the $\mathrm{SH}$ vortex lasted late into December 2015 as denoted by the lowEPV anomaly near the South Pole.

While all the 2015/16 NH winter months had average or above-average tropical momentum fluxes, the values for February 2016 were especially notable. Figure 9 shows the local standard deviation normalized momentum and heat fluxes at $40 \mathrm{hPa}$ as a function of latitude. The range of the previous Februaries (1980-2014) is given by the gray shading. The February 2016 momentum flux (Fig. 9a) is nearly 10 standard deviations above the climatology at $10^{\circ} \mathrm{S}$. The next largest value is in 1983 at nearly four

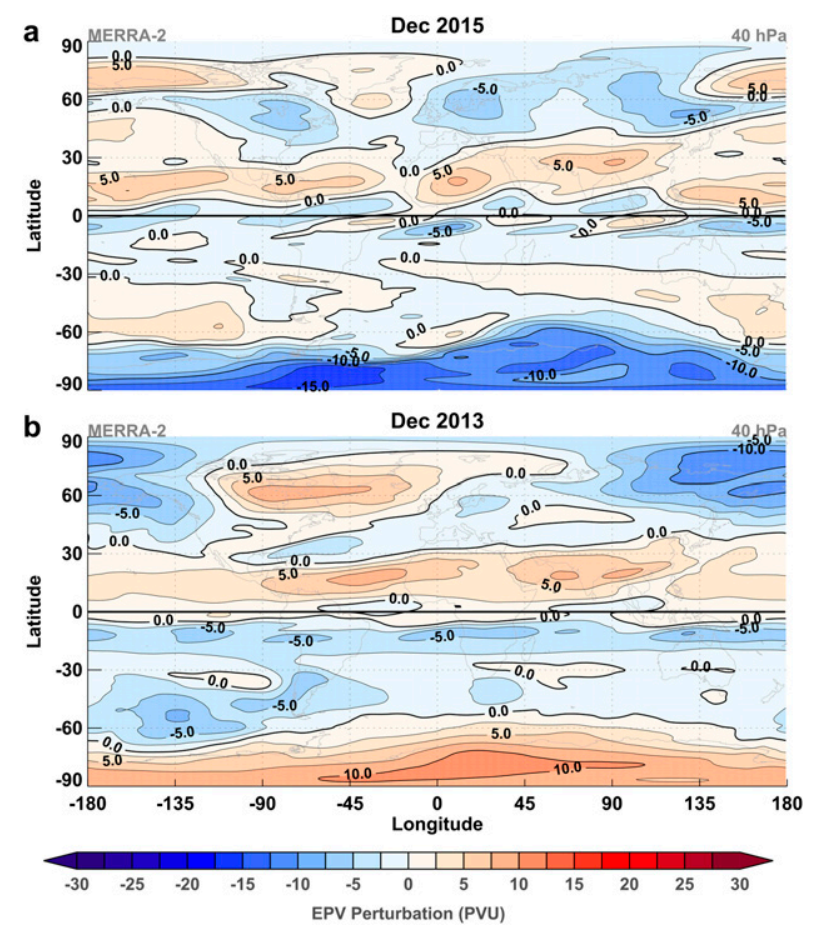

FIG. 8. The December monthly average EPV [potential vorticity units (PVU); 1 PVU $=10^{-6} \mathrm{~m}^{2} \mathrm{~s}^{-1} \mathrm{~K} \mathrm{~kg}^{-1}$ ] at $40 \mathrm{hPa}$ with the December MERRA-2 climate mean (1980-2014) subtracted for (a) 2015 and (b) 2013.

standard deviations, much less than the 2016 value. The 2016 momentum flux values are greater than five standard deviations from $20^{\circ} \mathrm{S}$ to $15^{\circ} \mathrm{N}$. As with the momentum fluxes, the 2016 heat flux (Fig. 9b) stands out from the other years, with only 1983 showing an equal peak value at $20^{\circ} \mathrm{N}$ (gray shading). Note that the 2016 heat fluxes are mainly positive north of the equator and negative south of the equator, indicating upward wave propagation (vertical EP flux vectors) in both hemispheres.

Figure 10 shows February normalized momentum fluxes as a function of latitude and pressure for four selected years: 2016 (disrupted QBO), 2014 (a recent more typical westerly QBO), 2011, and 1988 (the two years with large amplitude tropical horizontal momentum flux divergence). The large tropical values during 2016 are strongly focused at the 40- and 30-hPa levels with values greater than nine standard deviations. February 2016 also shows relatively large positive values $(>3)$ at $30^{\circ} \mathrm{N}$ and $100 \mathrm{hPa}$. The comparison year, 2014 (Fig. 10b), shows positive fluxes at $40 \mathrm{hPa}$ in the tropics; however, they are much smaller $(<2)$ than the 2016 values, and most of the domain shows negative values. As in 2013/14, westerlies continued throughout the 2010/11 winter, including February 2011 (Fig. 10c); however, February 2011 resembles 2014 more than 2016, with 

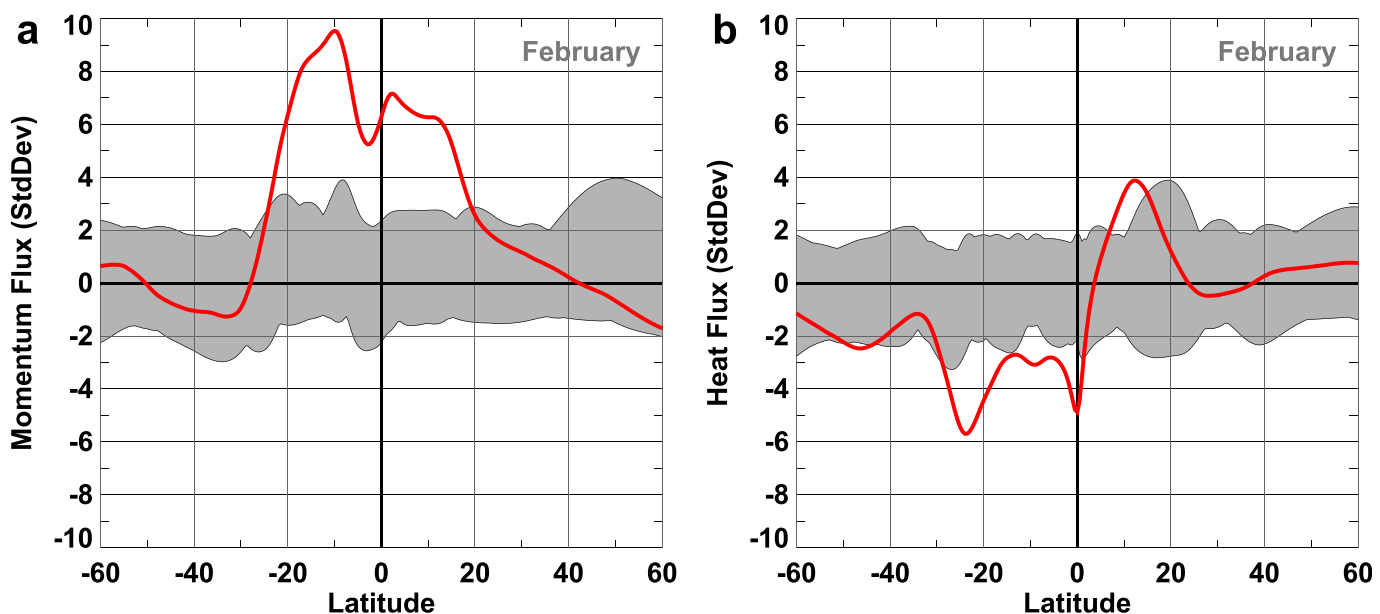

FIG. 9. Zonally averaged (a) momentum and (b) heat fluxes at $40 \mathrm{hPa}$ for February 2016 (red curve, $10^{\circ} \mathrm{S}-10^{\circ} \mathrm{N}$ ) and plotted as functions of latitude. The values are nondimensional in terms of standard deviations over the years 1980-2014. The gray shaded regions denotes the February normalized range over 1980-2014.

tropical momentum fluxes at $40 \mathrm{hPa}$ peaking near two standard deviations. February 1988 (Fig. 10d), like 2015/ 16 , was concurrent with a strong ENSO event along with westerlies in the equatorial lower stratosphere, and the
February 1988 tropical values are relatively large, peaking at over two standard deviations, although smaller than the February 2016 values. Overall, the 2014, 2011, and 1988 Februaries show negative momentum fluxes at
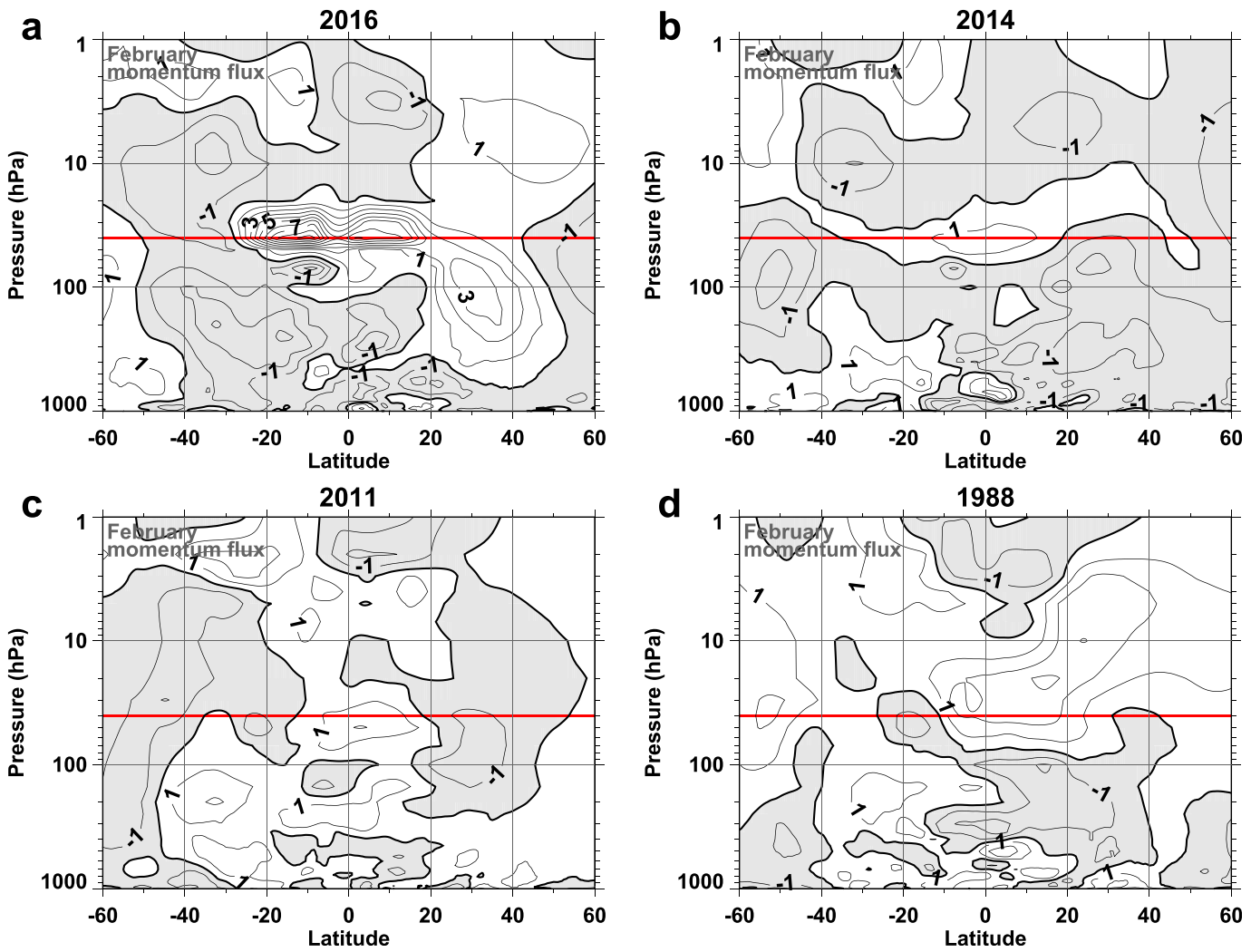

FIG. 10. February zonally averaged momentum flux for (a) 2016, (b) 2014, (c) 2011, and (d) 1988 as function of latitude and pressure. The values are nondimensional in terms of standard deviations over the years 1980-2014 with a contour interval of one standard deviation. Negative values are shaded gray. The red horizontal line denotes the 40-hPa level. 

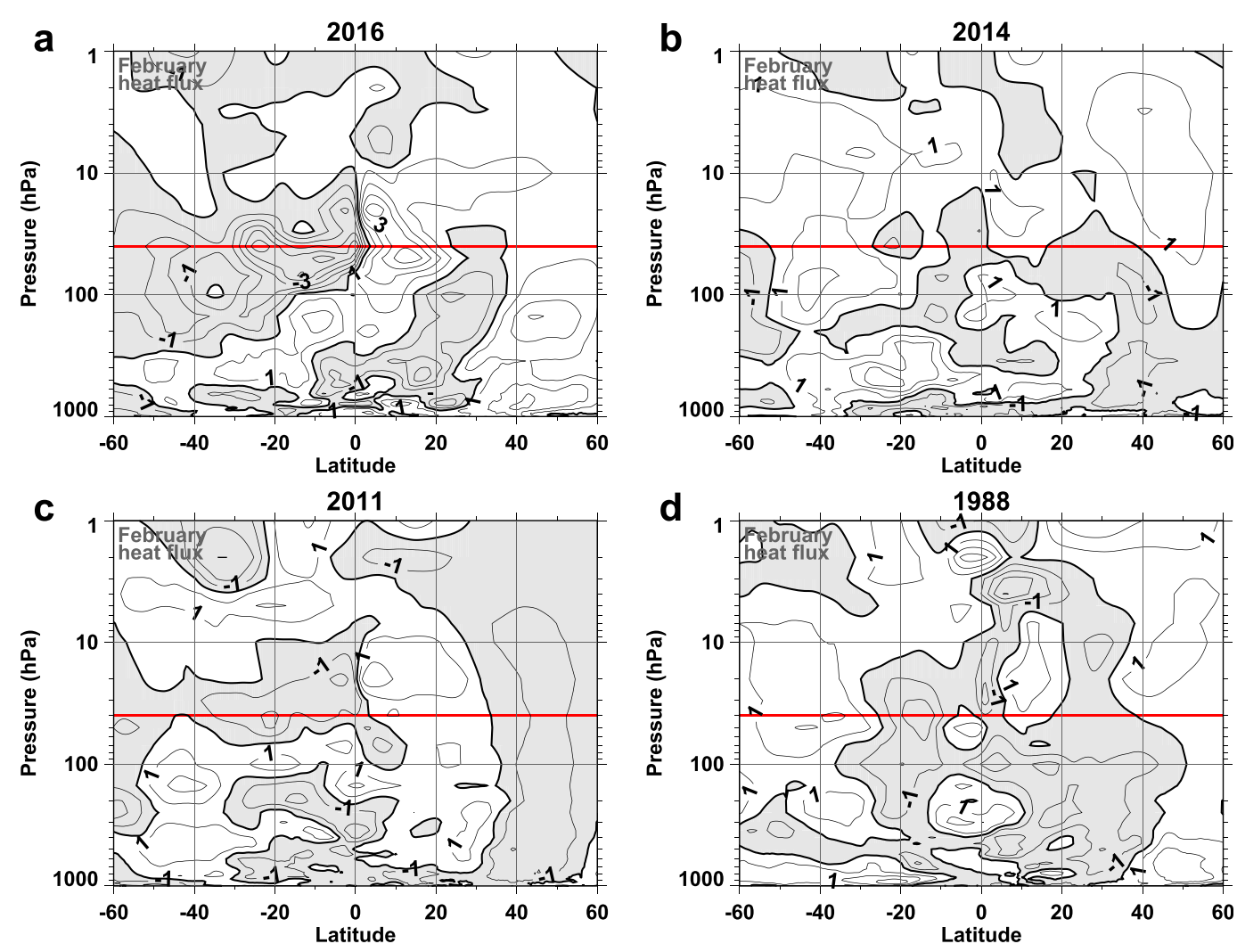

FIG. 11. As in Fig. 10, but for heat flux.

$30^{\circ} \mathrm{N}$ and $100 \mathrm{hPa}$, in contrast to 2016 . Note that February is past the peak month of equatorial horizontal momentum flux divergence for the comparison years (Fig. 5). Examination of corresponding plots for December and January (not shown) showed horizontal momentum fluxes as large as three standard deviations in the lower stratosphere during January 2014 and January 2011 and as large as two standard deviations in December 1987. These are similar to the peak values found in December 2015 and January 2016. None of the corresponding positive upper-tropospheric values are greater than approximately two standard deviations. Thus, February 2016 especially stands out for its strong horizontal momentum flux values in the $\mathrm{NH}$ upper troposphere and tropical lower stratosphere.

Figure 11 compares the February heat fluxes for the same four years. The largest values (from -5 to 4 standard deviations) are found in 2016 at $50 \mathrm{hPa}$ in the tropics. As at $40 \mathrm{hPa}$ (Fig. 9b), the field generally switches sign across the equator, indicating a strong upward EP flux component over most of the tropics. There are also stronger positive and negative values during 2016 in the Northern Hemisphere upper troposphere $\left(20^{\circ}-60^{\circ} \mathrm{N}, 150 \mathrm{hPa}\right)$ than is seen in the other three years. Figure 11 suggests that the tropical waves during 2016 are stronger than average, even in the Southern Hemisphere lower stratosphere. While not significant in the MERRA-2 momentum budget (Fig. 4), the vertical divergence of EP flux (dependent on the meridional heat flux) in the tropics at $40 \mathrm{hPa}$ is shown by Osprey et al. (2016) to be increasing in February 2016 and a leading term by March 2016 so that these fluxes may play a role in the later stage of the QBO disruption. In addition, the large amplitude meridional heat fluxes seen here in February 2016 suggest that the ECMWF analyses examined in Osprey et al. (2016) can be expected to have correspondingly larger amplitude fluxes.

Figure 12 presents the February anomalous EP flux vectors, again for the same four years. Note that these are the EP flux vectors normalized by their local standard deviations (section 2) to highlight the interannual variability and thus differ from the vectors plotted in Fig. 6d. February 2016 (Fig. 12a) shows larger than average upward fluxes poleward of the Northern Hemisphere tropospheric jet (red contours). The large fluxes into the stratosphere turn toward the tropics at about 40-30 hPa. Large amplitude regions of negative EP flux divergence (red shading) are seen in the tropics at those altitudes and in the Southern Hemisphere. In contrast, 2014 (Fig. 12b) shows reduced EP flux into the tropics in 

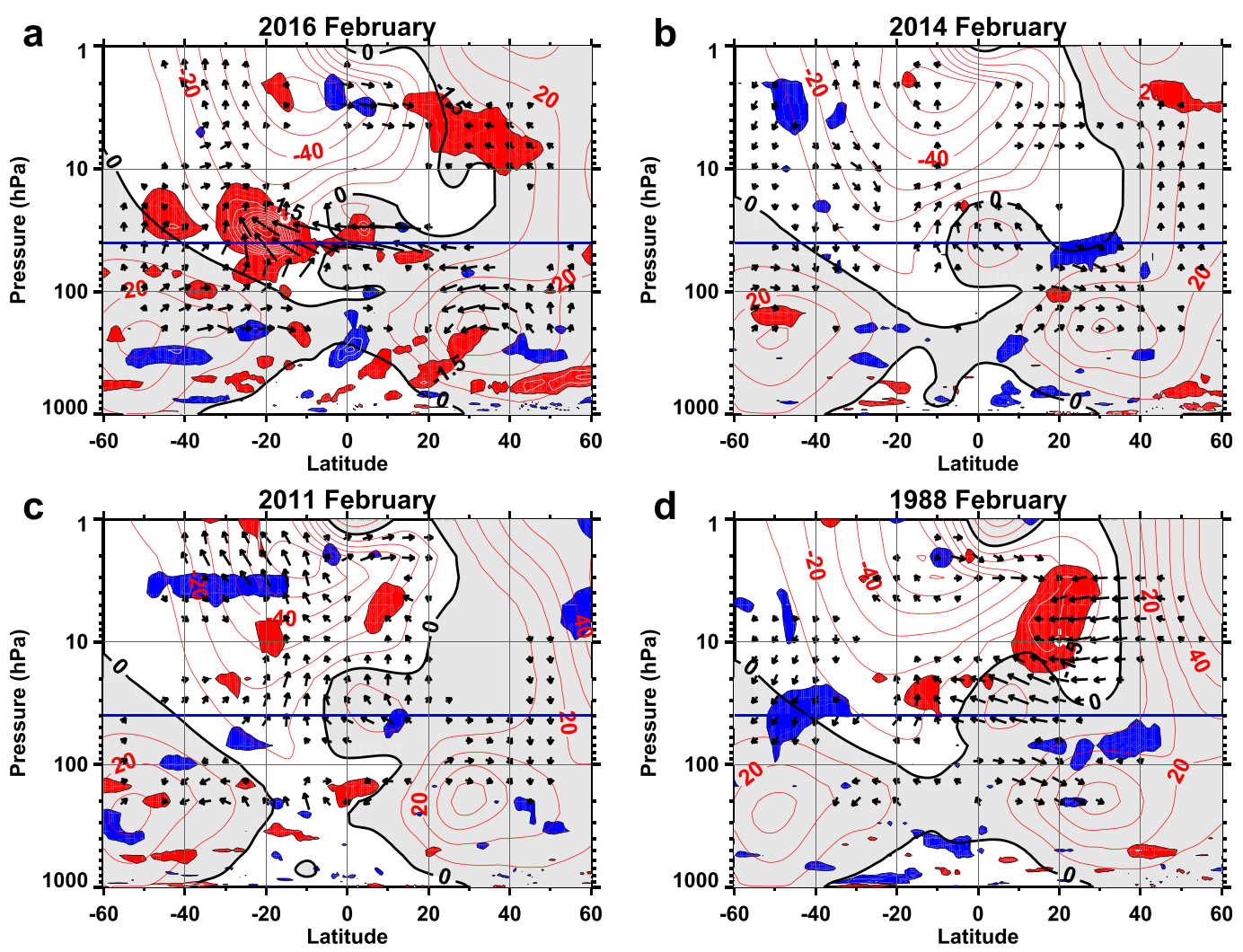

FIG. 12. February zonally averaged zonal wind $\left(\mathrm{m} \mathrm{s}^{-1}\right.$, with a contour interval of $10 \mathrm{~m} \mathrm{~s}^{-1}$; red contours, positive values gray shaded) for (a) 2016, (b) 2014, (c) 2011, and (d) 1988 as function of latitude and pressure. The arrows denote normalized EP flux deviations from the 1980-2014 February climatology and are normalized as described in section 2 and plotted so that $5^{\circ}$ of latitude corresponds to one standard deviation. The red (blue)-filled regions denote negative (positive) EP flux divergence anomalies (nondimensional standard deviations, with 0.5 contour interval; white contours). The filled contours start at \pm 1.5 . The blue horizontal line denotes the $40-h P a$ level.

the lower stratosphere (poleward arrows). Both 2014 and 2011 (Figs. 12b and 12c, respectively) show larger than average tropical EP flux vectors, although they are smaller than the 2016 case, more upward oriented, and not associated with large anomalous EP flux divergence. The 1988 case (Fig. 12d) shows anomalous EP flux vectors that are nearly equal in magnitude to February 2016; however, the tropical divergences are smaller than February 2016. None of the three additional Februaries examined in Fig. 12 show the large amplitude negative EP flux divergence values found in 2016.

Along with strong tropical wave activity throughout the 2015/16 winter, there was an especially large amplitude tropical wave breaking event during early February 2016. The NH polar winter of 2015/16 was extremely cold in December, and the polar vortex planetary waves were relatively weak until late January. The 2015/16 winter then had a very early major final warming event in early March (Manney and Lawrence 2016). As the polar planetary wave activity increased in late January, and a wave breaking event occurred, the tropics responded with an associated strong wave event. The exact origin of this strong tropical wave event likely involves some combination of stratospheric wave breaking and direct tropospheric forcing that we plan to investigate in future modeling studies. Figure 13 shows the evolution of this feature in EPV on the $530-\mathrm{K}$ potential temperature surface at 5-day intervals. The winter polar vortex (red shading) displayed a strong wavenumber 2 pattern on 31 January 2016 (Fig. 13a) that interacted with the tropical EPV (green shading) near $90^{\circ} \mathrm{E}$. This produced an intrusion of subtropical air (transparent shading) into the tropics and a wide-inlatitude "knot" of tropical EPV formed and propagated westward over equatorial Africa (Fig. 13b). By 10 February (Fig. 13c), the disturbance continued to propagate westward over the Atlantic Ocean and extended from South America to Africa. While the westward propagation slowed somewhat, 15 February found the EPV disturbance centered over South America, with a long 

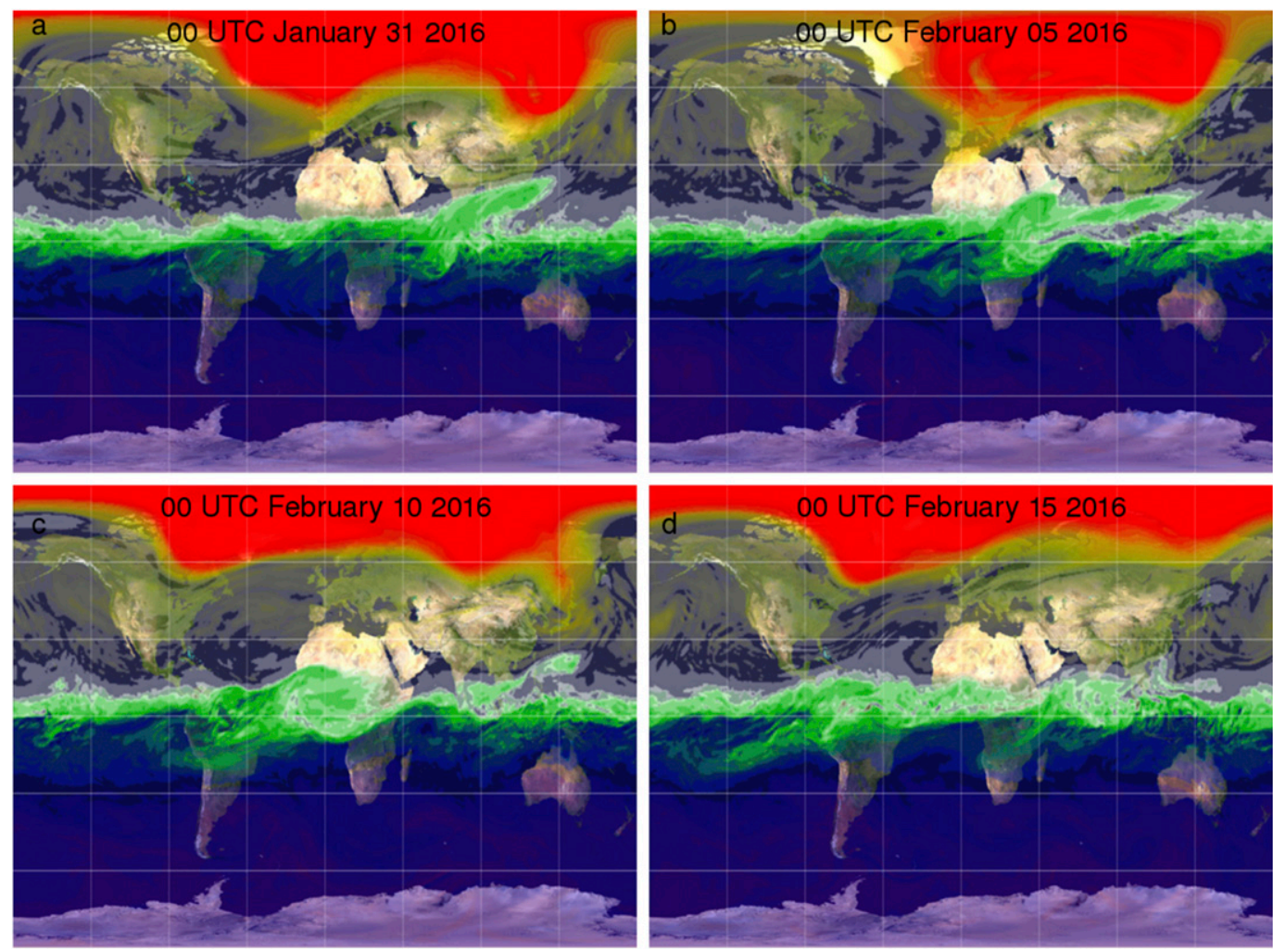

FIG. 13. EPV on the 530-K potential temperature surface for 0000 UTC on (a) 31 Jan, (b) 5 Feb, (c) 10 Feb, and (d) $15 \mathrm{Feb} 2016$. The green colors denote values from approximately -15 to $15 \mathrm{PVU}$, red denotes values $>100 \mathrm{PVU}$, and purple denotes values $<-50 \mathrm{PVU}$. Latitude lines at $60^{\circ} \mathrm{S}, 30^{\circ} \mathrm{S}, 0^{\circ}, 30^{\circ} \mathrm{N}$, and $60^{\circ} \mathrm{N}$. Longitude lines at $135^{\circ} \mathrm{W}$, $90^{\circ} \mathrm{W}, 45^{\circ} \mathrm{W}, 0^{\circ}, 45^{\circ} \mathrm{E}, 90^{\circ} \mathrm{E}$, and $135^{\circ} \mathrm{E}$. The $530-\mathrm{K}$ surface is approximately at $40 \mathrm{hPa}$ near the equator.

tail of tropical EPV extending south of the equator over the western Pacific. (Note that an animation of Fig. 13, including a comparison with $2013 / 14$, is available in the supplemental material.)

\section{Summary and conclusions}

The disruption of the QBO mean zonal wind during the 2015/16 NH winter was associated with record strong stratospheric tropical wave activity. This disruption was well captured by MERRA-2 (Fig. 1). The mean wind disruption was the only event of its kind seen since regular observation of the QBO began (Newman et al. 2016). Associated with this record disruption, the tropical wave momentum flux at $40 \mathrm{hPa}$, after very strong values during December-January, attained a record peak value in February 2016 (Fig. 3), the largest in magnitude of any month during the 35-yr MERRA-2 period. This tropical wave activity was especially focused at the 40-hPa level (Figs. 9 and 10). Initially in November-December 2015, the wave momentum fluxes crossed the equator, reaching the $\mathrm{SH}$ easterlies. The $\mathrm{SH}$ easterlies at $40 \mathrm{hPa}$ then intruded toward and eventually crossed the equator, effectively splitting the QBO westerlies (Fig. 6).

In summary, the boreal winter of 2015/16 showed

- record strong momentum and heat fluxes in the tropical lower stratosphere consistent with southward and upward wave propagation;

- at $40 \mathrm{hPa}$, the developing anomalous easterlies split the QBO westerlies into two distinct westerly jets; and

- a large amplitude tropical wave breaking event occurred in February 2016.

Evidence shown in Osprey et al. (2016) and in Figs. 10 and 12 suggests $\mathrm{NH}$ wave generation as the most likely source of the anomalous easterly acceleration. However, there is still the question of what forced the $\mathrm{NH}$ wave generation necessary to cause the 2015/16 QBO disruption. The 1987/88 and 2010/11 NH winters also showed large tropical momentum flux divergences in the tropical lower stratosphere; however, in those years, the waves were apparently not of sufficient magnitude to reverse the QBO, and westerlies prevailed throughout the winter. So the question remains about why some $\mathrm{NH}$ winters have increased momentum flux divergence and, 


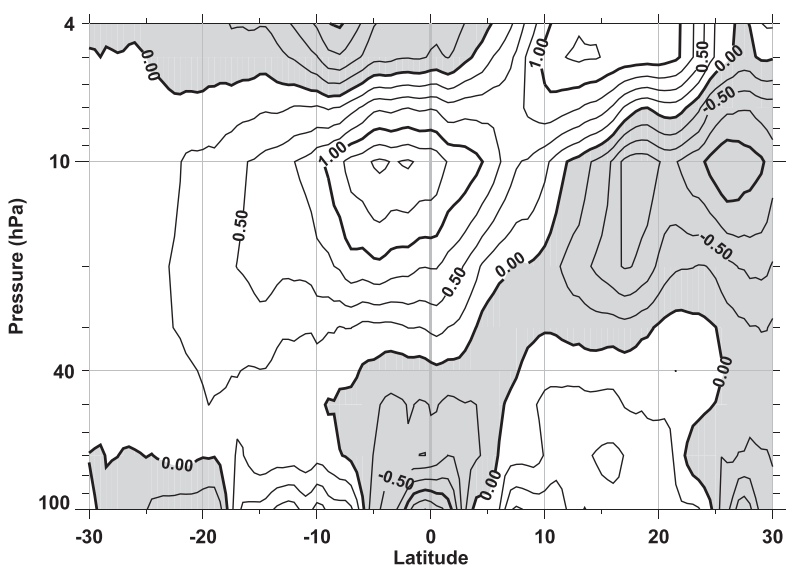

FIG. 14. The vertical component of the residual mean circulation (km month ${ }^{-1}$ ) averaged December 2015-February 2016 as a function of latitude and pressure. The multiyear (December 1980 February 2015) monthly means have been subtracted. Negative values are shaded.

although somewhat larger in 2015/16, what specific factors about the 2015/16 winter caused the reversal of the zonal mean zonal wind.

The origins of the 2015/16 NH winter increase in wave forcing needs further investigation. The increased wave forcing could have resulted from the naturally large stratospheric-tropospheric internal variability or possibly be tied to specific variability such at that associated with ENSO or changed global climate patterns. In particular, Newman et al. (2016, their Fig. 4) showed that the tropical upper-tropospheric temperatures were much warmer than the MERRA-2 climate record. Such warm temperatures may affect tropical and midlatitude wave generation and propagation.

In the climatological mean, winter season Rossby waves propagate upward and equatorward and generally extend into the QBO westerlies. Figure 12 showed that the February 2016 upward and equatorward EP fluxes were larger than for the MERRA-2 February average and suggests a connection between the midlatitudes and the tropics. However, the heat fluxes for February 2016 (Fig. 11) showed large values that could be taken to imply more local equatorial Rossby modes as being responsible for the anomalous momentum fluxes, so this possibility is not entirely ruled out. However, the relatively small contribution of the vertical EP flux divergence to the zonal mean equatorial momentum budget (Fig. 4) during the acceleration of the anomalous easterlies suggests that the heat fluxes played a relatively small role. We are planning future modeling experiments to investigate the specific sources of the anomalous momentum flux.

Along with the specific cause of the increased wave forcing, the need to understand why the waves were focused so strongly near $40 \mathrm{hPa}$ in altitude remains. The QBO westerlies extended from approximately 100 to $5 \mathrm{hPa}$ in the $\mathrm{NH}$ fall of 2015, yet the easterly acceleration was strong in a more limited vertical region, approximately $40-30 \mathrm{hPa}$. This wave focusing allowed the full wave-induced easterly acceleration to be applied consistently over several months to a relatively confined vertical subregion of the QBO westerlies, adding up to the significant rearrangement of the tropical lowerstratospheric winds by the end of March 2016. The intrusion of the easterlies resulting from Rossby waves is unexpected given the modeling results of O'Sullivan (1997) showing only changes in the zonal mean wind gradients and not the equatorial jet maximum, so more modeling investigation is needed to understand these acceleration.

Another possibility is a baroclinic, barotropic, or inertial instability associated with the westerly QBO jet. The negative regions of $\bar{q}_{\phi}$ of Shuckburgh et al. (2001) suggest the possibility of barotropic shear instability associated with the QBO jets. However, the regions of negative $\bar{q}_{\phi}$ are mainly associated with the increasing QBO westerlies when the meridional wind shears are largest. Figure 7 showed that $\bar{q}_{\phi}$ was positive during the anomalous easterly acceleration, making instability of the large-scale flow unlikely in this case. Moreover, the mean instability would need to be maintained over the several months that characterized the anomalous easterly acceleration.

More detailed diagnostic and model forecast studies are needed to resolve meridional circulation changes associated with this 2015/16 disrupted QBO and to test the ability of seasonal forecast systems to encompass and predict such a disruption of the QBO. As noted by Newman et al. (2016) and Osprey et al. (2016), the normally downward propagating westerlies showed an upward propagation (or displacement) in 2016 at altitudes above approximately $30 \mathrm{hPa}$ in the lower stratosphere (Fig. 1). Figure 14 plots the December 2015-February 2016 vertical component of the residual mean circulation $\bar{w}^{*}$ (with multiyear means removed). The calculated $\bar{w}^{*}$ field shows upward motion above approximately $40 \mathrm{hPa}$ and centered at approximately $5^{\circ} \mathrm{S}$. The upward values of about $1 \mathrm{~km} \mathrm{month}^{-1}$ are the same order of magnitude as the observed upward displacement and suggest that the meridional circulation response to the easterly acceleration at $40 \mathrm{hPa}$ played a role in the observed upward displacement. The upward progression of the westerlies can therefore be expected to modify the transport and distribution of stratospheric trace gases and aerosols.

The 2015/16 disruption of the QBO provides an opportunity for improving forecasting in the tropical lower 
stratosphere, especially on seasonal time scales, as it provides a specific example of how the QBO responds to changes in wave forcing. In this context, the winters of 1987/88 and 2010/11 provide additional examples of strong wave momentum forcing that lacked the zonal wind reversals, so any forecasting improvements should encompass these winters as well. Along with developing the ability to forecast a major disruption of the QBO, the QBO disruption of 2015/16 may require reevaluation of the normally high QBO seasonal prediction skill (Scaife et al. 2014).

Acknowledgments. We thank the three anonymous reviewers whose comments led to many improvement to the initial manuscript. This research was performed with funding from the NASA Modeling, Analysis and Prediction program and the NASA Atmospheric Composition Modeling and Analysis Program. The MERRA-2 fields were obtained from the NASA Earth Observing System Data and Information System (https://earthdata. nasa.gov). The specific MERRA-2 fields used are listed in the references.

\section{REFERENCES}

Andrews, D. G., J. R. Holton, and C. B. Leovy, 1987: Middle Atmosphere Dynamics. International Geophysics Series, Vol. 40, Academic Press, 489 pp.

Baldwin, M. P., and Coauthors, 2001: The quasi-biennial oscillation. Rev. Geophys., 39, 179-229, doi:10.1029/1999RG000073.

Bosilovich, M. G., and Coauthors, 2015: MERRA-2: Initial evaluation of the climate. NASA Tech. Memo. NASA/TM-2015104606/Vol. 43, 145 pp. [Available online at https://gmao.gsfc. nasa.gov/pubs/docs/Bosilovich803.pdf.]

Coy, L., K. Wargan, A. M. Molod, W. R. McCarty, and S. Pawson, 2016: Structure and dynamics of the quasi-biennial oscillation in MERRA-2. J. Climate, 29, 5339-5354, doi:10.1175/ JCLI-D-15-0809.1.

GMAO, 2015a: MERRA-2 inst3_3d_asm_Np: 3D, 3-hourly, instantaneous, pressure-level, assimilation, assimilated meteorological fields, version 5.12.4. GSFC Distributed Active Archive Center, accessed 1 June 2016, doi:10.5067/QBZ6MG944HW0.

- 2015b: MERRA-2 inst3_3d_asm_Nv: 3D, 3-hourly, instantaneous, model-level, assimilation, assimilated meteorological fields, version 5.12.4. GSFC Distributed Active Archive Center, accessed 1 June 2016, doi:10.5067/ WWQSXQ8IVFW8.

, 2015c: MERRA-2 instM_3d_asm_Np: 3D, monthly mean, instantaneous, pressure-level, assimilation, assimilated meteorological fields, version 5.12.4. GSFC Distributed Active Archive Center, accessed 1 June 2016, doi:10.5067/ 2E096JV59PK7.

— , 2015d: MERRA-2 tavgM_3d_trb_Np: 3D, monthly mean, time-averaged, pressure-level, assimilation, turbulence diagnostics, version 5.12.4. GSFC Distributed Active Archive Center, accessed 1 June 2016, doi:10.5067/2YOIQB5C3ACN.

Hamilton, K., 1982: Some features of the climatology of the Northern Hemisphere stratosphere revealed by NMC upper atmosphere analyses. J. Atmos. Sci., 39, 2737-2749, doi:10.1175/1520-0469(1982)039<2737:SFOTCO>2.0.CO;2.

Holt, L. A., M. J. Alexander, L. Coy, A. Molod, W. Putman, and S. Pawson, 2016: Tropical waves and the quasi-biennial oscillation in a $7-\mathrm{km}$ global climate simulation. J. Atmos. Sci., $\mathbf{7 3}$, 3771-3783, doi:10.1175/JAS-D-15-0350.1.

Kawatani, Y., K. Hamilton, K. Miyazaki, M. Fujiwara, and J. A. Anstey, 2016: Representation of the tropical stratospheric zonal wind in global atmospheric reanalyses. Atmos. Chem. Phys., 16, 6681-6699, doi:10.5194/acp-16-6681-2016.

Lindzen, R. S., and J. R. Holton, 1968: A theory of the quasibiennial oscillation. J. Atmos. Sci., 25, 1095-1107, doi:10.1175/ 1520-0469(1968)025<1095:ATOTQB > 2.0.CO;2.

Manney, G. L., and Z. D. Lawrence, 2016: The major stratospheric final warming in 2016: Dispersal of vortex air and termination of Arctic chemical ozone loss. Atmos. Chem. Phys., 16, $15371-$ 15 396, doi:10.5194/acp-16-15371-2016.

Molod, A., L. Takacs, M. Suarez, and J. Bacmeister, 2015: Development of the GEOS-5 atmospheric general circulation model: Evolution from MERRA to MERRA2. Geosci. Model Dev., 8, 1339-1356, doi:10.5194/gmd-8-1339-2015.

Newman, P. A., L. Coy, S. Pawson, and L. R. Lait, 2016: The anomalous change in the QBO in 2015-2016. Geophys. Res. Lett., 43, 8791-8797, doi:10.1002/2016GL070373.

Osprey, S. M., N. Butchart, J. R. Knight, A. A. Scaife, K. Hamilton, J. A. Anstey, V. Schenzinger, and C. Zhang, 2016: An unexpected disruption of the atmospheric quasi-biennial oscillation. Science, 353, 1424-1427, doi:10.1126/science.aah4156.

O'Sullivan, D., 1997: Interaction of extratropical Rossby waves with westerly quasi-biennial oscillation winds. J. Geophys. Res., 102, 19 461-19 469, doi:10.1029/97JD01524.

Pawson, S., K. Labitzke, R. Lenschow, B. Naujokat, B. Rajewski, M. Wiesner, and R.-C. Wohlfart, 1993: Climatology of the Northern Hemisphere Stratosphere Derived from Berlin Analyses: Monthly Means. Meteorologische Abhandlungen, Vol. 7, Freien Universität Berlin, 299 pp.

Scaife, A. A., and Coauthors, 2014: Predictability of the quasibiennial oscillation and its northern winter teleconnection on seasonal to decadal timescales. Geophys. Res. Lett., 41, 17521758, doi:10.1002/2013GL059160.

Shuckburgh, E., W. Norton, A. Iwi, and P. Haynes, 2001: Influence of the quasi-biennial oscillation on isentropic transport and mixing in the tropics and subtropics. J. Geophys. Res., 106, 14 327-14 337, doi:10.1029/2000JD900664. 